\title{
A Socio-Cognitive Perspective on the Factors Affecting Malaysian Business Students' Learning when Spoken in English in a Second-Language Classroom
}

\author{
Siti Amirah Ahmad Tarmizi $(\mathbb{D})$, Najihah Mahmud $(\mathbb{D})$, Amaal Fadhlini \\ Mohamed $(D)$, Ariezal Afzan Hassan $(D)$, Nazatul Syima Mohd Nasir $[D$ \\ and Nor Hazwani Munirah Lateh \\ Department of English, Universiti Malaysia Kelantan, Kelantan, Malaysia
}

\begin{abstract}
The current literature review of second-language learning (SLL) views second-language (L2) development as a complex system comprised of ecological interactions between multi-faceted agents that fluctuate over time, in constantly changing environments. This concept is in contrast with two dominant theories that have framed many existing studies in the field of SLL: the cognitive theory that sees cognition as the nucleus of SLL, and the sociocultural theory that maintains that SLL occurs as a result of social and cultural forces. However, little research has been done to explore the dynamic nature of SLL in a deeply comprehensive manner, in order to explain the phenomenon. Therefore, this study aims to fill this gap of knowledge via a detailed investigation of how Business students at a Malaysian public university developed their English-speaking abilities in an L2 classroom context. A group of 31 undergraduate Business students (30 females and one male), as well as their English teacher, were involved in this case study, collecting data through classroom observations, interviews, a survey, as well as relevant curriculum documents, including academic records. The findings from the qualitative analysis via a unique model proposed in the study, based on a socio-cognitive theory, have revealed that learning to speak English is a complex process involving the ongoing physiological activities of adaptation and alignment. The notion of co-dependency exists between individual learners and their physical and conceptual resources, constituted in the social environment of the classroom, in order to perform the appropriate learning actions.
\end{abstract}

Keywords: second language learning; socio-cognitive; speaking

\section{Introduction}

The spread of English as the world language, has resulted in the need for people to be well-versed in that language; and this includes those involved in the 
Business sector, to help them manage their business as effectively as possible. Following this, Business English has received considerable attention, particularly within the field of education, in order to find ways to improve learners' English skills and the competencies that are required in the business world (Tratnik et al., 2017; Xu et al., 2021).

In Malaysia, Business English is often described as a branch of English for Specific Purposes (ESP) that focuses on developing learners' communication skills, such as presenting ideas, making suggestions, and negotiating (Baharum, 2013; Khamis \& Wahi, 2021). As such, teaching and learning materials are typically centred around enhancing productively spoken English, where learners are put in reallife situations and expected to converse in that language throughout the activities (Baba, 2013).

Although this situational syllabus, in some manner, manages to promote learners' active experimentation with the target language, the goal to produce graduates with business communication skills is unfortunately yet to be achieved (Abdul Hamid, 2014; Ganeson, 2018; Khamis \& Wahi, 2021). There are many factors that have been found to contribute to this problem. Baharum (2013), for instance, reported that teachers' difficulty in conforming to contemporary teaching methods often leads to many other problems, such as inadequate teaching and learning materials, and learners' poor motivation.

While this may be true, this study believes that there must be more to the explanation. Driven by intellectual curiosity, this present study intends to investigate the situated process of learning-spoken English in an L2 classroom at a public university in Malaysia, in order to apprehend the underlying complexities of the said phenomenon.

\section{Literature Review}

There has been an intense debate going on in the field of SLL pertaining to ontological and epistemological matters. The former is concerned with what embodies the notion of SLL, while the latter focuses on how researchers perceive the issue (Block, 2003). There are two major stances that seem to lead the way researchers interpret and understand the SLL phenomenon: 1) the cognitive stance, which theorises that SLL is a process that occurs inside the individual heads of learners (Ortega, 2013; Suzuki et al., 2019) and 2) the socio-culturalist stance, which posits that SLL as the outcome of social and cultural activities (Lantolf, 2000a, 2000b; Lantolf et al., 2018).

The cognitive perspective postulates that $\mathrm{L} 2$ learners' mental operations are vastly conceptual, computational and amodal (Harnish, 2002; Van Patten \& Benati, 2015). This implies that learners are genuinely individualistic, in the sense that they autonomously regulate their own L2 acquisitional process; and, even if there are any external forces that come to play, they are only secondary (Atkinson et al., 2018; Ortega, 2013). This theoretical bias that refuses to acknowledge the fact that cognition is environmentally embedded has led to broad criticism across the field, especially from the more socially driven theorists --- the socio-culturalists.

Unlike the cognitive view of "supreme" thought processes, the socio-cultural 
approach concerns the involvement of social and cultural interactions in L2 learners' processes of meaning-making (Lantolf et al., 2018). This holds that the collective activity of learning always precedes learners' individual development, that is, it is through socio-culturally mediated artefacts that learners restructure their own cognitive operations; and thereafter, they internalise the learnt language (Lantolf, 2000a). Thus, as opposed to the cognitive notion, which believes that L2 learning occurs primarily in learners' private minds, the socio-cultural perspective presumes that the construction of L2 language in learners is cross-functional and crosscultural.

Even though the socio-cultural approach is rather successful in offering a wider perspective of the cognitive domain in language learning, it has also come into criticism for being too externally focused, and, thus, it pays little heed to individual learners' differences (Atkinson et al., 2018; Lee, 2015). This has called forth a more recent argument among SLL scholars about the necessity to revisit the role of both the cognitive and the socio-cultural constituents in these SLL theories.

\subsection{The dynamic approach of second-language learning}

The growing view that there is a loophole in SLL theories, whereby they fail to simultaneously address both the internal and the external variables of $\mathrm{L} 2$ learners, has opened the door for the consideration of a more dynamic and integrated approach to language learning, such as a socio-cognitive perspective. This contemporary theory repudiates the concept of "solitary cognition"; and it supports the "self-in-context" view instead (Atkinson et al., 2018; Hiver \& AlHoorie, 2016).

This present study is specifically inspired by a socio-cognitive approach, as proposed by Dwight Atkinson. Unlike other socio-cognitive frameworks that focus on human interactions, Atkinson considers both the human and the nonhuman elements in the environment, which determine the overall interactions (Atkinson, 2010; Atkinson et al., 2007); making it thereby more comprehensive to investigate the process of learning L2 speaking in the study. There are three fundamental principles of Atkinson's socio-cognitive approach: 1) the inseparability principle, 2) the learning-as-an adaptive principle, and 3) the alignment principle.

\subsubsection{The inseparability principle}

This principle maintains that the social and the cognitive aspects of language acquisition, learning and use are inseparable; and consequently, separating them for a careful investigation is irrelevant. This is because human brains are an open system that incessantly and complicatedly adapt to worldly circumstances on a moment-by-moment basis (Atkinson, 2011). With reference to Gee's (1992) principle of the social mind that believes wisdom (cognition) is both "in the head" and "in the world", Atkinson (2010) described the concept of integrated cognition by using two terms: extended and embodied cognition.

Extended cognition is situated in activity bound to social, cultural and physical contexts, while embodied cognition is grounded in bodily states and actions (Atkinson, 2010, p.599). In essence, Atkinson suggests that SLL is an intricate system that is neither wholly socially driven nor cognitively driven, but rather it 
is multi-dimensional and multi-directional, in which learners' mind, body and world operate together (Atkinson, 2002, 2010, 2011; Atkinson et al., 2018).

\subsubsection{The learning-is-an adaptive principle}

This principle is based on the idea that humans are social animals; and consequently, cognition assists humans to adapt to their environment, in order to survive and thrive (Atkinson, 2010). Although this concept of adaptation is relatively novel in SLA/SLL, it has been long established in the field (though it may not always be represented by the same term) to denote individuals' natural reliance on their socio-cultural resources, when communicating their wants and needs.

Baldwin et al. (1996), who studied language development in young children, for example, found that infants that are continuously mediated by meaningful social cues, such as toys and the parental gaze, are more likely to be able to name the objects around them. This shows that infants innately learn relevant cultural knowledge, as a part of their adaptive actions, in order to achieve joint understandings via language.

\subsubsection{The alignment principle}

This principle signifies humans' involuntary capacity to automatically co-ordinate their interactions with other people and the material world around them, for their collective benefits (Atkinson, 2010, 2014; Atkinson et al., 2007). Atkinson (2010) construed alignment as being the major engine of SLL as it reflects the primary state, whereby learners become unconditionally engaged in the complex process of learning. The manifestation of alignments in individuals is caused by the mirror-neuron system in the human brain that is responsible for making sense of other people's actions and intentions (Fogassi, 2011). Alignments can be embodied in various forms, such as language, emotional states, body positionings, joint attention and thought, as well as paying attention to distinctive socio-environmental cues and artefacts (Atkinson, 2010, 2014; Atkinson et al., 2018).

In conformity with the socio-cognitive principles, this current study takes the view that the complex phenomenon of learning spoken English can be fully comprehended, when the social and cognitive determinants of the learning process are concurrently explored. As such, this study seeks to delve into the intricate nature of how business students at a public university develop their L2 speaking abilities in a situated classroom context, investigating the synergy between the individual and external factors. Based on the said objectives, the following research question has been formulated:

In what ways do the internal and external factors affect Business students' learning of L2 speaking?

\section{The Methods}

This study employed a qualitative case study, which, according to Yin (2009, 2014), is a useful medium to investigate a phenomenon of interest in an allinclusive manner, within its real-life context. The ability of case studies to capture 
the socially constructed dynamic realities (Stake, 1995; Yilmaz, 2013) may help this study to describe in detail the intricate connection between the learners' internal and external factors during the process of learning L2 speaking.

\subsection{The study context and the participants}

This study was conducted at a public university in the north-eastern corner of Peninsular Malaysia, involving a group of 31 second-year undergraduate Business students undertaking the English for Business Communication course and their respective teacher. These participants were carefully selected by using purposive sampling to gain information-rich cases related to the phenomenon of interest (Palinkas et al., 2015, p.533). Thus, after some discussions with the university administrators and English teachers, the researchers decided to observe this group of students, based on the nature of the course that focused on speaking skills, as well as their willingness to participate in the study. Furthermore, focusing on a single group of students can help researchers to delve into the subtleties and peculiarities of the individual cases better (Gustafsson, 2017).

The teacher was a 29-year-old female Malay, who had more than six years of teaching English experience at the tertiary level. The students, on the other hand, consisted of 30 female students and one male student, with 28 of them Malay, and three Chinese. Their ages ranged from 20 to 23 years. Since the students' English proficiency was gauged, according to their results in the Malaysian University English Test (MUET) ${ }^{1}$. The classroom was, therefore, of a mixed proficiency, comprising Band 2 (limited), 3 (modest) and 4 (good) students. Table 1 below provides the summary of the participants' profile in this study, based on the questionnaire that they answered before the data collection started.

Table 1: Profiles of participants in the study

\begin{tabular}{|c|c|c|c|c|c|c|}
\hline Participants & Gender & Race & Age & $\begin{array}{l}\text { MUET } \\
\text { band } \\
\text { score }\end{array}$ & $\begin{array}{l}\text { Number } \\
\text { of years } \\
\text { in } \\
\text { studying } \\
\text { English }\end{array}$ & $\begin{array}{l}\text { Previous } \\
\text { experience } \\
\text { in the } \\
\text { English- } \\
\text { speaking } \\
\text { environment }\end{array}$ \\
\hline 1 & Male & Chinese & 21 & 4 & 16 & Yes \\
\hline 2 & Female & Chinese & 21 & 3 & 16 & Yes \\
\hline 3 & Female & Chinese & 20 & 4 & 15 & Yes \\
\hline 4 & Female & Malay & 20 & 3 & 15 & Yes \\
\hline 5 & Female & Malay & 20 & 2 & 15 & Yes \\
\hline 6 & Female & Malay & 20 & 2 & 14 & No \\
\hline 7 & Female & Malay & 20 & 3 & 16 & Yes \\
\hline 8 & Female & Malay & 20 & 2 & 15 & No \\
\hline 9 & Female & Malay & 21 & 3 & 15 & No \\
\hline 10 & Female & Malay & 21 & 2 & 15 & No \\
\hline 11 & Female & Malay & 21 & 2 & 16 & Yes \\
\hline 12 & Female & Malay & 21 & 2 & 16 & No \\
\hline 13 & Female & Malay & 21 & 3 & 16 & No \\
\hline 14 & Female & Malay & 21 & 3 & 15 & No \\
\hline
\end{tabular}

\footnotetext{
${ }^{1}$ MUET is a high-stakes test run by the Malaysian Examinations Council, in order to measure English language proficiency, largely for university admissions (Rethinasamy \& Chuah, 2011).
} 


\begin{tabular}{|l|l|l|l|l|l|l|}
15 & Female & Malay & 21 & 2 & 15 & No \\
16 & Female & Malay & 21 & 2 & 15 & No \\
17 & Female & Malay & 21 & 2 & 15 & No \\
18 & Female & Malay & 21 & 3 & 15 & Yes \\
19 & Female & Malay & 21 & 3 & 15 & Yes \\
20 & Female & Malay & 21 & 3 & 15 & Yes \\
21 & Female & Malay & 21 & 3 & 16 & Yes \\
22 & Female & Malay & 21 & 3 & 16 & Yes \\
23 & Female & Malay & 21 & 3 & 16 & Yes \\
24 & Female & Malay & 21 & 2 & 15 & No \\
25 & Female & Malay & 21 & 3 & 15 & No \\
26 & Female & Malay & 21 & 2 & 15 & Yes \\
27 & Female & Malay & 21 & 2 & 15 & No \\
28 & Female & Malay & 21 & 2 & 15 & No \\
29 & Female & Malay & 23 & 2 & 17 & No \\
30 & Female & Malay & 23 & 2 & 17 & No \\
31 & Female & Malay & 23 & 4 & 18 & Yes \\
\hline
\end{tabular}

\subsection{Research instruments}

To enhance the validity of the data analysis and the interpretations, this case study employed a triangulated approach; and it collected the data through multiple instruments, as follows:

\subsubsection{Classroom observations}

The observations took place in an English-for-Business Communication classroom for a period of one whole semester (14 weeks). This compulsory two-credit hour course required the students to attend the class twice a week. However, since the focus of the current study is on learning speaking skills, only the speaking lessons were observed by the researchers, thereby resulting in eight classroom observations.

Considering that observation is an excellent method to explore subjects in their naturally occurring context (Driscoll, 2011) the researchers decided to use this instrument largely to examine how the students went about their learning activities in the speaking classroom, with special attention being given to their interaction and behaviour. This information was important, in order to help inform the researchers of the instructional practices and all the possible factors that contributed to the intricate process of learning L2 speaking.

\subsubsection{Interviews}

There were two types of interviews used in the study:

\subsection{2a Semi-structured interview}

This interview was conducted after the classroom observation, which was completed, with six voluntary student-participants and the teacher. All of the six students were individually interviewed, in order to get their opinions on their personal experiences with the English language, as well as their perceptions of the speaking lessons. One focus-group discussion was also conducted with the same participants, in order to further investigate the topic. The synergistic effect of discussion and debate in a focus group might encourage the participants to 
produce more comprehensive data, which might not be achievable in the individual interviews (Kitzinger, 1994, 1995; Nyumba et al., 2018).

The teacher, meanwhile, was individually questioned to gain background knowledge about the teaching and learning practices in the L2 speaking classroom, as well as the factors that she believed had contributed to the students' process of learning via L2 speaking.

\subsection{2b Unstructured interview (stimulated recall)}

Stimulated recalls were used in the study, in order to explore the possible interactions between the individual and the contextual factors, and their influence on learning via L2 speaking. The ability of this interview to revive the memories and thoughts of the participants (Jamshed, 2014) enabled the students in the study to explain their specific actions and behaviours, which had been observed in the classroom.

Unlike the semi-structured interview that involved six pre-determined students, this stimulated recall interview involved randomly selected student participants in the classroom. This is because the researchers had no idea in advance, of which participants would demonstrate significant actions or behaviours that could be explored to gain further information.

\subsubsection{A Questionnaire}

A Questionnaire in the study was conducted to obtain the student-participants' background information. The students were given 15 minutes to answer the questionnaire, which was set in both English and in the Malaysian language, prior to classroom observations. This demographic survey was instrumental in providing a holistic and all-encompassing explanation in the analysis of the research data.

\subsubsection{Curriculum documents and students' academic records}

This study relied on the university policy and course outline, in order to gain information about the design of the English-for-Business Communication course. The students' university entrance test results (MUET) and their summative course assessment (particularly on their speaking skills) were also analysed, in order to examine the student-participants' linguistic profile.

\subsection{The data analysis}

There were three theoretical tools used in the present study to analyse the collected data:

\subsubsection{The Activity Theory}

Although the Activity Theory is socio-culturally driven, its view of learning as a complex mediated collective activity that gradually involves individuals' active participation, and other people and the artefacts available in situated social contexts (Foot, 2014; Hasan \& Kazlauskas, 2014), is not only consistent with the socio-cognitive concept of the "self-in-context"; but it also confirms a detailed and structured examination of the contextual influence over the self in "self-incontext". This allows the study to better discern the complexity and the dynamic 
nature of the learning-speaking activities that occurred in the investigated classroom. In addition, the graphical model of the Activity Theory is also practical, in order to visually illustrate the relationships between the factors involved. Consequently, the Activity Theory was employed within the socio-cognitive framework in this study, mainly for the interpretation and the organisation of the themes, in order to yield an answer to the research question.

During the analytical phase to answer the research question, the researchers continuously linked the recurrent themes and the sub-themes to the theoretical lens of the Activity Theory. The identified themes and the sub-themes were conceptualised and arranged, according to six different components of an activity system, as shown in Figure 1:

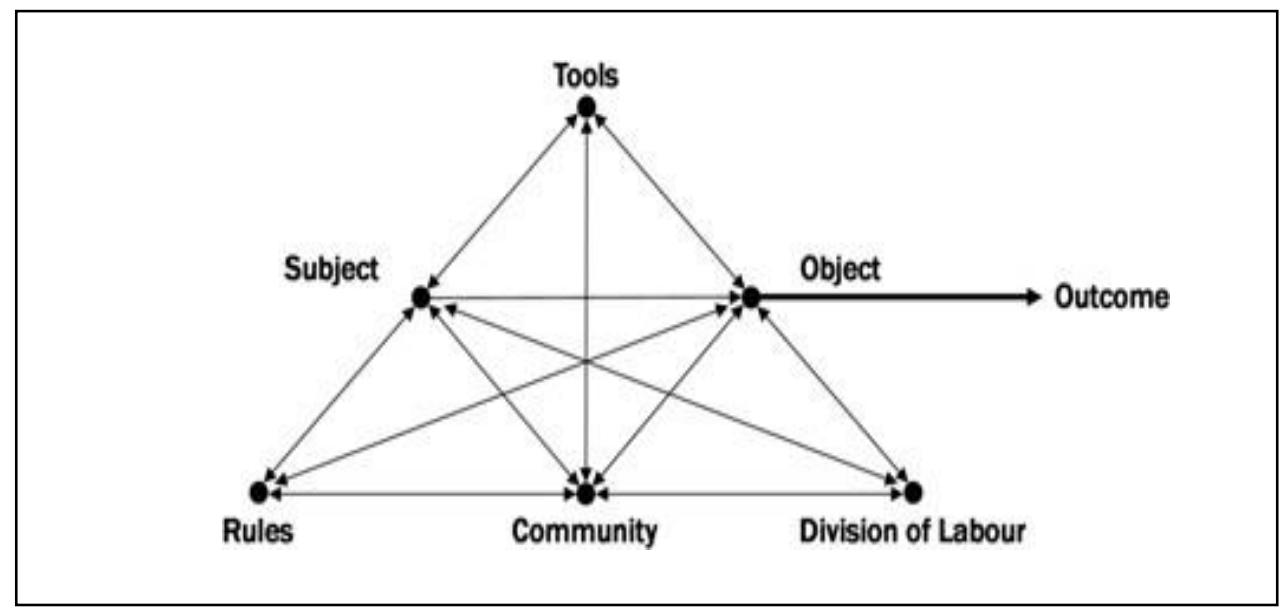

Figure 1: The activity-system model (Engeström, 1987, p.78)

Once the activity system of learning L2 speaking was constructed, a more in-depth analysis of the interconnections between and within the elements of the activity system was conducted, in order to explore their effects on the process of learning speaking. This was done by examining the activity structure: the roles of the subjects undertaking the activity, the motives of the overall activity, the goals associated with the actions of different individual subjects, the use of mediating tools, the community of practice, its rules and regulations, and the horizontal allocation of the tasks between the community members (Barnard, 2010; Hasan \& Kazlauskas, 2014).

This present study also used Tae-Young's (2007) model of motivation, in combination with the Activity Theory, in order to further explore the motivational dynamics of the students in learning to speak English. According to Tae-Young (2007), motivation is derived from the subjects' need, coupled with the object, to develop a motive. This motive, then, merged with the goal and the participation, to produce the motivation of the L2 learners (see Figure 2). 


\section{Need + Object $\longrightarrow$ Motive + Goal + Participation $\longrightarrow$ Motivation}

Figure 2: The relationship between the motives, goals and motivation (Tae-Young, 2007, p.37)

As shown in Figure 2, the motives, goals and motivation are all interconnected in forming the learners' inner drive, which directs them towards the learning objectives. The interaction among them is highly complicated; and it is easily influenced by the dynamics or tensions that emerge within an element, or between other elements of the activity system involved. Consequently, with this additional model, the researchers delved into the student-participants' underlying motives, goals and motivation, which constantly modified their learning performance throughout the speaking classroom. It should be made clear that, although the Activity Theory was used in the study to examine the symbiotic relationships between the individual learners and their in-class environment, it is given little merit in the subject(s), as idiosyncratic actors in social lives when they are viewed as being socially motivated by nature (Battista, 2015). Following this, Bachman and Palmer's (1996) communicative language use model, along with that of Chapelle et al. (1997), the COE model were used in the study to respectively represent the exhaustive components of individual learners' cognition and their social classroom contexts to gain an undivided socio-cognitive interpretation.

\subsubsection{Bachman and Palmer's (1996) communicative language use model}

Since this model views language use as an interaction between language users and their context (Harsch, 2017), it was, therefore, an appropriate mechanism to represent the intricate connections between individual and external factors in students' learning of L2 speaking. Figure 3 below demonstrates several of the components that this model hypothesises play a role in an individual's language usage.

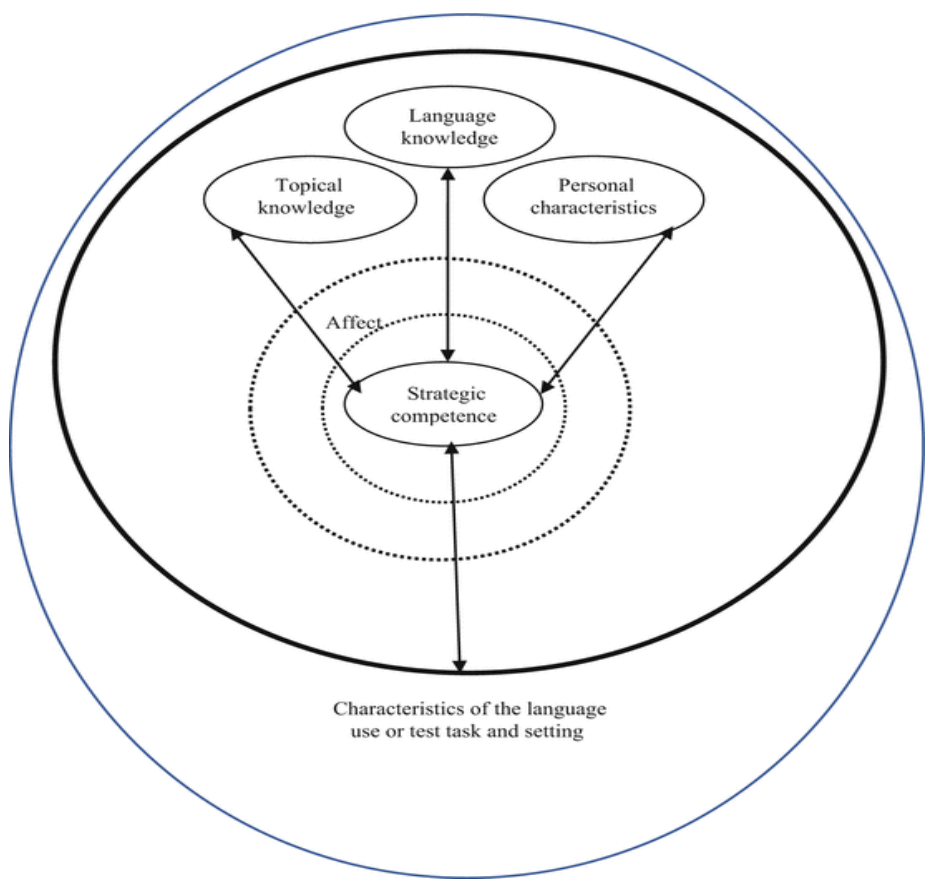

Figure 3: Components of language usage and language-test performance (Bachman \& Palmer, 1996, p.63) 
As displayed in Figure 3, there are several attributes of language users that influence their communicative language ability, namely: 1) language knowledge, 2) topical knowledge, 3) personal characteristics, 4) strategic competence, and 5) affective factors. Language knowledge implies the numerous language knowledge or skills in a user's memory (Luoma, 2004; Seong, 2014). Personal characteristics refer to individual basic features, such as sex, age and nationality, whereas topical knowledge signifies the user's knowledge of different topics that he/she applies to a language-use situation (Luoma, 2004; Zhang,2018).

When someone uses a language, the two knowledge components (language knowledge and topical knowledge) and personal characteristics are facilitated by two other components: strategic competence (the user's meta-cognitive organisation and the monitoring of the situation) and the affective factors (the user's emotional responses to the situation) (Bachman \& Palmer, 1996; Zhang et al., 2021). All these five features that define an individual language user's attributes (as represented by the second largest and bold circle) closely communicate with the context of language use (as represented by the largest thin circle).

While Bachman and Palmer's model of communicative language ability does emphasise the interrelationships of various aspects, which comprise the language knowledge stored in a person's mind with the external surroundings (Luoma, 2004), it does not explicitly specify the contextual properties of language usage. Consequently, to compensate for this limitation, the model of Chapelle et al. (1997) COE was used in the current study, in order to further and more clearly define the contextual variables in an L2 classroom.

\subsubsection{The model of Chapelle et al. (1997), the COE model}

The TOEFL 2000 Committee of Examiners' (COE) model was developed by Chapelle et al. in 1997; and it was strongly influenced by Hymes (1971), Canale and Swain (1980), as well as Bachman (1990) (Chapelle et al., 1997; Luoma, 2004). Figure 4 demonstrates the model. 


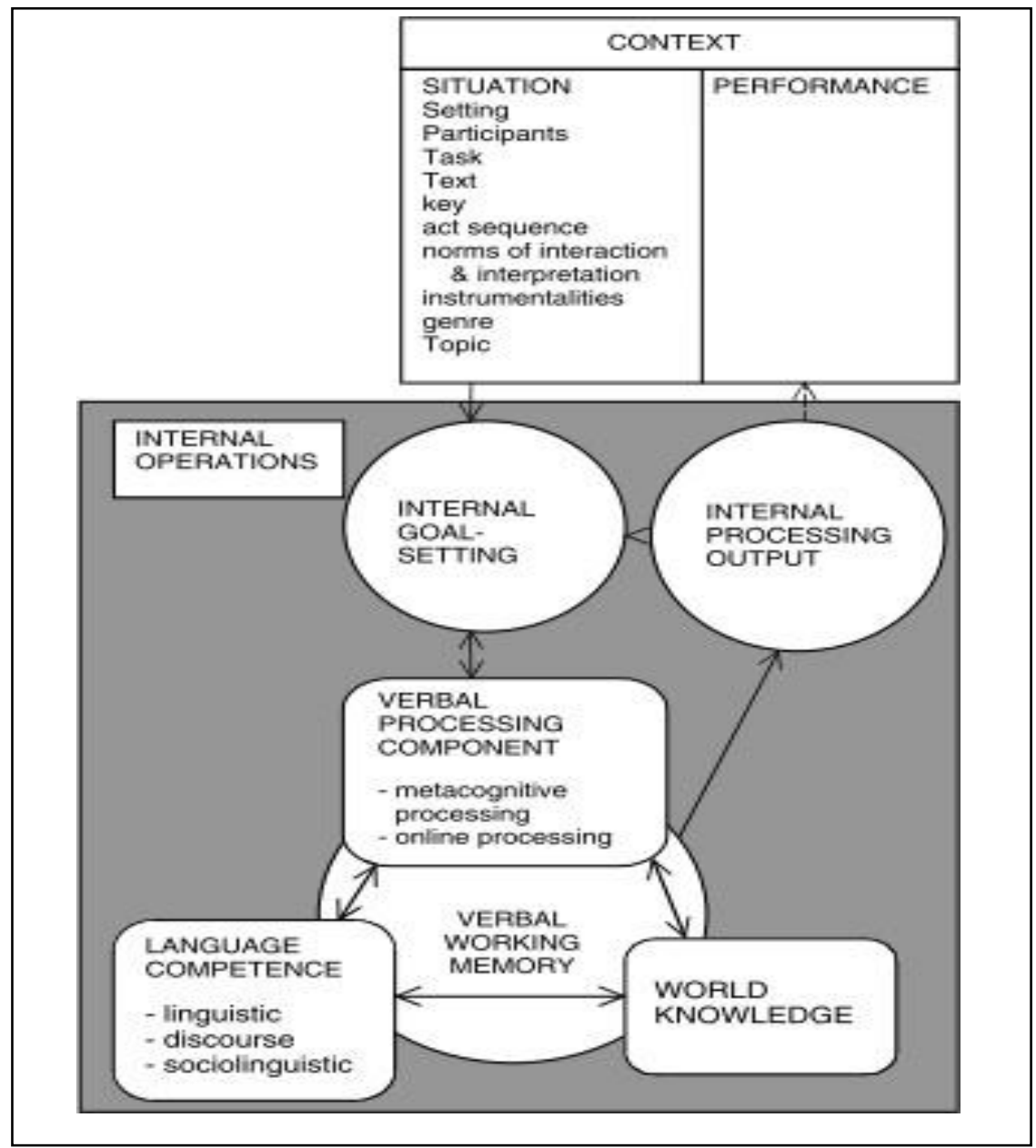

Figure 4: The COE working model of communicative language use in an academic context (Chapelle et al., 1997, p.5)

As indicated in Figure 4, the COE model consists of two main parts: 1) the internal operations and 2) the context. The internal operations (as illustrated in the grey box) refer to language users' abilities, involving a range of mental-processing components that are externally interrelated. It begins with internal goal setting (extrinsic/intrinsic motivation), which actively interact with the major internal operations that occur in verbal working memory (which views the interactions of a verbal processing component, language competence and world knowledge) (Piggin, 2012). All this interactive processing then results in internal-processing output that can be externally manifested through performance (Chapelle et al., 1997).

The context in the COE model consists of two interconnecting constituents: 1) situation and 2) performance. The situation is a variety of academic circumstances that are believed to influence language use-setting (i.e. physical environment), participants (i.e. individuals and their roles), task (i.e. activity with a specified goal), text (i.e. type of language used to complete a task) and topic (i.e. the content information that is being addressed); while the performance demonstrates the language user's response to the context (Luoma, 2004, p.111). 
As previously mentioned, the model of Chapelle et al. (1997), the COE model was used in the present study, in order to describe in detail the context of language usage in Bachman and Palmer's model of communicative language ability. As such, only the "CONTEXT" part was taken from the COE model, since the model of Bachman and Palmer was adopted for elucidating the individual process of language production.

\section{Results}

The analysis through the lens of the Activity Theory revealed a dynamic interplay between the inner and outer forces that either positively or negatively influenced the participating students' learning from speaking on a moment-by-moment basis. The individual factors (subjects) identified in the study were: attitudes, beliefs and feelings about English, prior experiences, language proficiency, anxiety, self-confidence, strategies for learning from L2 speaking, and the subjective purpose of learning (e.g. motives, goals, and motivation).

The external factors that were also identified in the study were the socioenvironmental factors that reside in the classroom, including the explicit object of the overall activity (i.e. the course objectives), the tools employed (e.g. teacher, peers, classroom activities and technology), the community (e.g. the teacher and the peers), the rules (e.g. classroom-activity management, cultural norms and practices), and the division of labour (e.g. teacher-led and student-led). These two strands of factors (individual and external) did not impact the students' learning of L2 speaking independently, or mutually exclusively; but, rather, they were highly inter-related and overlapping in their influence on the students' learning to speak English (see Figure 4).

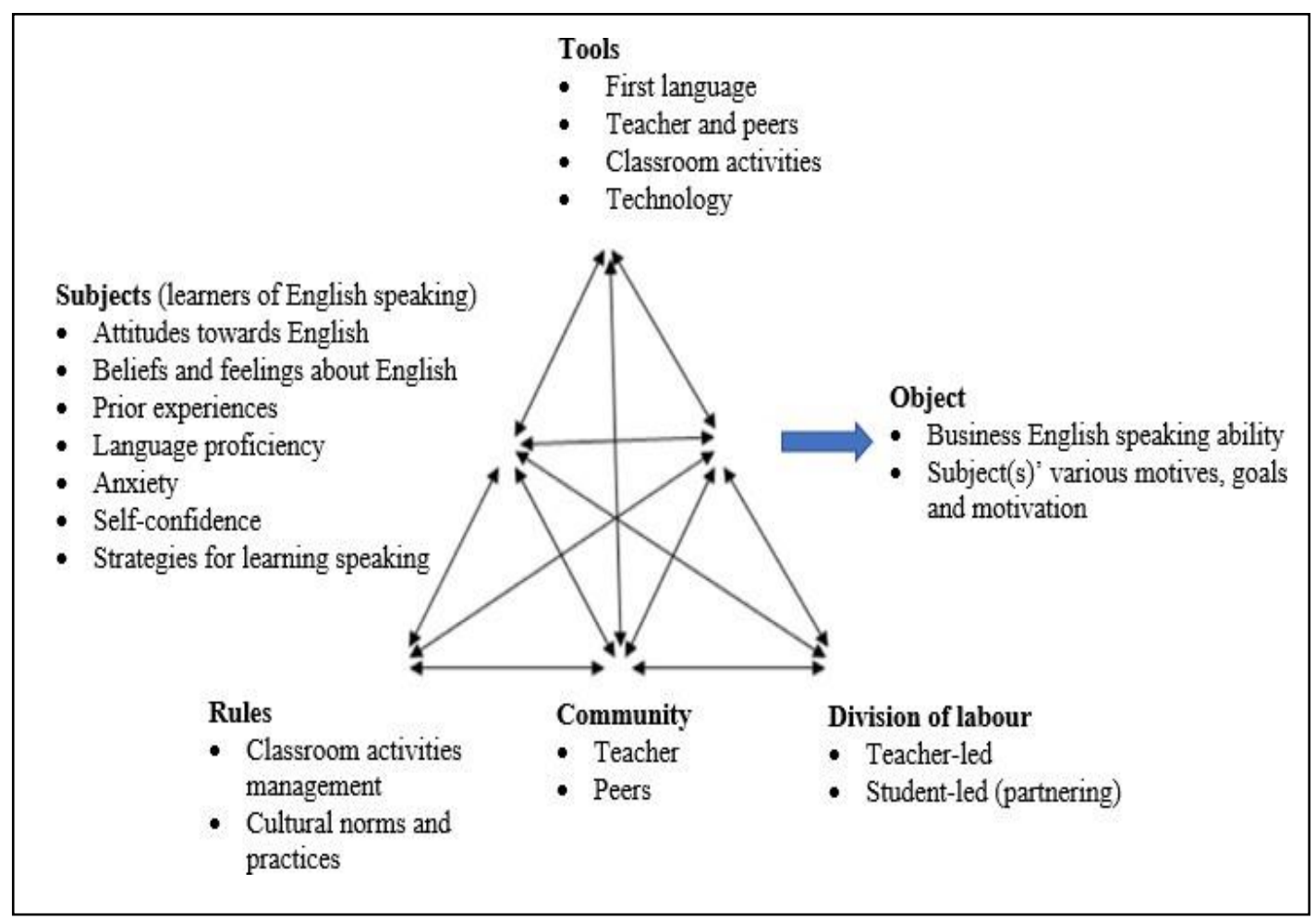

Figure 4: The activity system of learning from spoken English 


\subsection{Subjects}

Although all the students in the study showed positive attitudes towards learning spoken English, their learning behaviours were, however, varied across the individuals. This variance was found to have resulted from their diverse underlying motivations, which were largely influenced by their beliefs and feelings about English, and their previous experiences.

The students' beliefs and feelings about English were found to be highly associated with their perceptions on the value of English in their lives. Some perceptions were derived from their own life experiences (e.g. using English to communicate with friends from other races), while various others came from their own needs (e.g. English is important for a better career opportunity).

The students' prior life experiences in the study seemed to provoke different reactions in them; and these influenced their overall beliefs about English. Those who experienced a good use of English in life might think learning it was useful, while those who had scarcely experienced the language, might possibly think otherwise.

The students' language proficiency was found to be intricately interwoven with self-confidence, anxiety, the use of the first language (L1), and the strategies for learning from another spoken language. Those with limited English proficiency were found to be more apprehensive of their language inadequacy, and, consequently, they had little confidence to use the language in the classroom; whereas those with better English proficiency had a positive influence on their confidence level, and, thus, they proactively used the language.

Anxiety in the study was experienced by most of the students with poor Englishlanguage abilities. Most of these students were too conscious of people judging their grammatical mistakes; and they were afraid of being labelled as uneducated. This had consequently caused them to resort to various destructive avoidance strategies, such as passively depending on their L1 during the partner discussion, and closely reading scripts during the in-class role-playing presentation.

The students' self-confidence was found to be highly inter-related with their language proficiency and subsequent anxiety. The low-competent students displayed low self-confidence, when they were reported to be unwilling to speak in English, and by making mistakes throughout the process of learning. The more competent students, on the other hand, showed higher levels of self-confidence, when they appeared to have a greater control over the learning activities in the classroom.

The students' strategies for learning speaking were found to be closely intermingled with their speaking ability. Students with limited language skills used memory strategies, or the act of remembering the language for the sake of storing and retrieving information (Oxford, 2013) a great deal during the classroom activities. Meanwhile, students with better oral production appeared to adopt various other constructive strategies, such as cognitive and metacognitive abilities, which involve reasoning, monitoring and voluntary 
attention (Ma \& Oxford, 2014; Oxford, 2013).

It was revealed that the students' motivation significantly influenced their strategies for learning to speak English. Thus, when the students, regardless of their English competence, wished to perform well during the role-playing presentation, they turned to various accommodating strategies that would assist them to reach the intended goal (e.g. to memorise the dialogue for the lesscompetent students, or to speak as naturally as possible for the better skilled students).

\subsection{The tools}

This study found that the students highly utilised their L1 to help them deal with the intricacies of the L2. They, however, reported significant differences in terms of their intentions in using the L1. Those with lower English proficiency were more inclined to use the L1 to help them to accomplish the task in the classroom; while those with better English proficiency were more likely to use the L1 to gain better understanding of the L2.

Both the teacher and the peers acted as mediating tools in the study, when they provided both intellectual and emotional support to the students. Nevertheless, the findings revealed that students with less self-confidence were more willing to seek assistance from their peers, than from the teacher. This was different to more confident students, who wished to improve their L2, and, hence, opted for a more knowledgeable source: the teacher.

Classroom activities in this study served as a primary tool for learning to speak English. It was found that there were two aspects of the classroom activities that seemed to exert an influence on the students' learning process: types and topics. Many of the students informed that they were more interested in activities that were more interactive (e.g. role-playing) than those who were not (e.g. doing vocabulary practices in a textbook). However, their excitement did not seem to last long, when they were found to only enjoy the discussion part of the roleplaying (with partners), and not the presentation, about which they were highly anxious. For the topics, the students argued that any subject that was well-known to them, or important for their future career, would heighten their interest to learn; and, consequently, they would make extra efforts to communicate in the target language.

In terms of technology, the findings revealed that almost every participating student resorted to their smartphone (e.g. to Google word meanings) when they were unable to receive help from their teacher or peers in the classroom. This was especially true among those students with restricted English competence.

\subsection{The Community}

In this study, teacher and the peers not only functioned as a tool for learning, but also as a classroom community, whereby their collective activities formed a bond that in some ways influenced the process of learning to speak English. It was found that the teacher had positive relationships with the students when all of them expressed their strong liking for her. The teacher's positive personality, as 
well as affectionate and humorous attitudes had developed favourable emotions in the students, which, in turn, helped them to compensate for their individual weaknesses. Unfortunately, the relationships among the students were found to be quite the opposite. Many of the students argued that they did not receive enough emotional support from their peers, when they showed unsupportive behaviours in the classroom, such as refusing to speak in English during the roleplaying discussion and displaying a judgmental look during the presentation.

\subsection{The rules}

It was found that the rules set by the teacher for the classroom activities in the study defined the students' learning of the spoken English. The findings showed that, when the teacher allocated a short period of time for the discussion activity (for the role-playing) and focused more on the presentation, this caused different responses from the learners. Those with limited English competence were observed writing down their dialogues, while the better students appeared to be quite naturally practising their spoken English with their partner during the discussion.

This study also discovered that cultural norms and practices influenced the students' behaviours in the classroom. Living in a society that placed a high value on teachers, some students, for example, believed that they had the inclination to always respect the teacher. This had resulted in them putting in their best effort to participate in the classroom, in order to please their teacher. Having said that, not all the students' actions were socially motivated. This could be seen, when a few students argued that it was their personal aspiration to become proficient in English that had motivated them to perform in the classroom.

\subsection{Division of labour}

In this study, the ways the classroom activities were divided among the community members seemed to have had an influence on the students' motivation. There were two main approaches to the division of labour found in the study: 1) teacher-led, and 2) student-led. The teacher-led activities mostly occurred during the vocabulary practices, where the teacher controlled the learning path and assigned the students some practices from the textbook. Since this learning setting placed the students in an individual role, with little interaction occurring between them, it might have instilled a sense of boredom in the students, when they reported to being less interested in the said activities.

In contrast, the findings disclosed that most of the students favoured the studentled activities (partnering), since it gave them the opportunity to take charge of their own learning. Being able to work together with their peers afforded them the opportunity of developing feelings of security, which then motivated them to explore the target language without reservation.

\subsection{The Objective}

There were two types of objective identified in the present study; and they were highly complicated; since they were intricately connected with other elements in the activity system: 1) the explicit focus of the activity, and 2) the subjective purpose of the activity. The former entails the course objectives (i.e. to develop 
speaking abilities); whereas the latter encompasses the students' individualised drives for learning to speak English (i.e. motives, goals and motivation).

The findings revealed that the subjects' motives, or the reasons behind the students' determined urge to achieve the objective of the activity were mostly associated with their personal desire to improve themselves, in addition to career purposes. However, these students' motives seemed to have little effect on their learning process, when the data showed that the students' learning behaviours were conditionally dependent, and closely driven by their specific missions, or goals. To illustrate, due to their deficient L2 knowledge, some students decided to read from their scripts during the role-playing presentation (to have a perfect performance), although this action could be harmful for their own learning.

That is to say, the students' overall effort, or motivation in learning to speak English, was extremely vigorous and in a state of constant change. The interactions between individual and external factors along the learning process could either interfere or stimulate their motivation towards the learning objectives on occasions.

5. Discussion: L2 speaking in the classroom, as an integrated microsystem As the core claim of a socio-cognitive approach is that mind, body and world function interactively in second-language acquisition (SLA) (Atkinson, 2011, p.143), it would be inconclusive to investigate the process of learning to speak English, without first considering the whole picture of how cognition is embedded in the L2 environments. This is preferrable to treating the individual learners in the researched classroom as an isolated entity. This study viewed them and their learning, as a complex situated activity system, in which learning is highly distributed - not only across the human community, but also in terms of the environmental cues and conventional operations that co-constitute the system (Atkinson, 2002). This concept of co-dependency between minds (learners) and their socio-material environments in socio-cognitive SLA is termed "the inseparability principle" (Atkinson, 2010).

Following this principle, this study presents the Situated Microsystem Model of the L2 English-Speaking Classroom, or the SM Model, using a model adapted from Bachman and Palmer's (1996) communicative language usage, along with the model of Chapelle et al. (1997) COE, in order to represent the complexities of the system that account for the process of learning spoken English in an L2 classroom, as shown in Figure 5: 


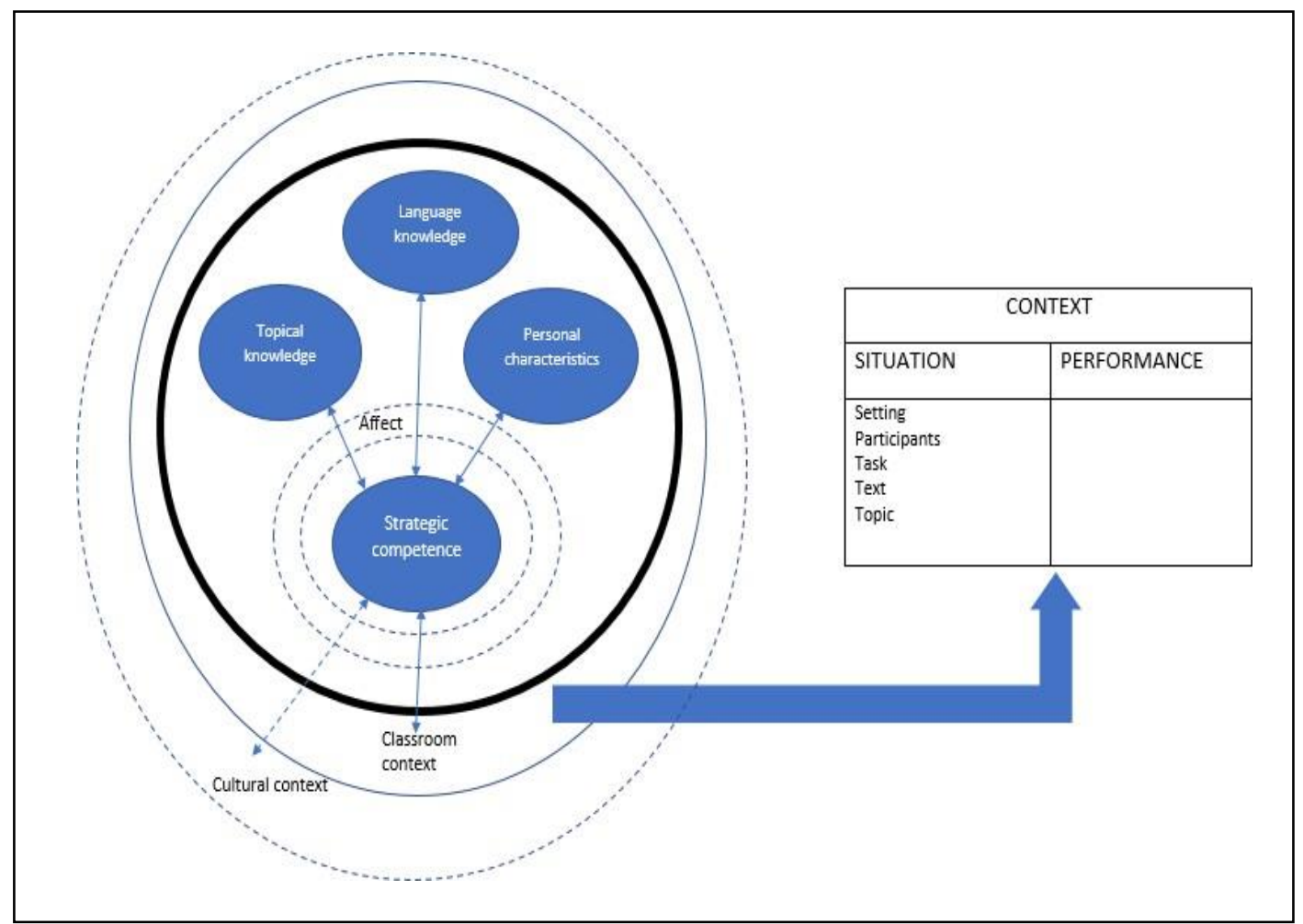

Figure 5: A situated microsystem model of L2 English speaking classroom (SM Model)

Figure 5 illustrates the L2 English-speaking classroom as a situated microsystem, in which the students are involved throughout in the simultaneous construction of their speaking ability, both "in the learner's head" and "in the world". The bold circle represents the cognitive part of the learner (Bachman \& Palmer, 1996; Luoma, 2004), or the central mechanism that governs the operations of the five elements that shape the cognition: 1) strategic competence, 2) affect, 3) language knowledge, 4) topical knowledge, and 5) personal characteristics.

\subsection{Strategic competence}

Strategic competence is the most critical part of cognition; since it demonstrates the interaction between learners' higher-order processing and their L2 environments (Bachman, 1990; Bachman \& Palmer, 1996; Luoma, 2004). This competence in the study can be represented by the students' discernible course of actions in the classroom, such as using L1 during the role-playing discussion, reading scripts, or speaking naturally during the role-playing presentation.

\subsection{Affect}

The affective part of learners in this study was associated with their attitudes, motivation and anxiety. All of these three factors co-influenced the strategic competence in mediating the other three components: language knowledge, topical knowledge and personal characteristics.

\subsection{Language knowledge}

Both the students' L1 and L2 knowledge served as a unified cognitive commodity in this study, when it allowed them to function in the social space of the speaking 
classroom. The facility of L1 to promote the shared understanding between what language users might have driven the students to go beyond the narrowly defined linguistic cues and to transcend culturally defined language boundaries (Wei, 2018 , p.25), so that they could perform well in L2 speaking.

This was mostly evident among the less-competent students, whose anxious minds sought comfort in their L1 to solve problems and to make progress in the speaking activities. This showed that language was indeed a part of the system that learners strategically employ to enhance their cognitive processing when constructing knowledge (Wei, 2018; Wiley \& García, 2016).

\subsection{Topical knowledge}

In this study, the students' topical knowledge demonstrated that human cognition is socially extended, when most of the students were inspired to learn to communicate in English, due to their situational life experiences concerning language usage. Their motivation to improve their quality of life, particularly in their future career, may indicate that these students learnt English-,speaking by virtue of their ongoing participation in a socially oriented world, rather than as a solitary cognitive occurrence (Atkinson, 2011, 2014).

\subsection{Personal characteristics}

The students' personal characteristics were also actuated throughout the process of learning to speak English, when they significantly influenced the students' learning actions. As shown in the findings, most of the less proficient students displayed introverted personalities, when they claimed to be shy in the classroom. However, when they were found to closely refer to their scripts during the roleplaying presentation, because of their fear of being embarrassed by social others (peers); this might indicate that the students' internal characteristics were indeed a twofold construct of collectivity and individuality that would betoken many other social actions (Tomasello, 2014).

Meanwhile, the thin circle outside the bold circle (in Figure 5.1) denotes the contextual factors that co-interacted with the learners' cognition throughout the learning process of L2 speaking. There were five consequential elements in the classroom context, according to Chapelle et al. (1997): 1) setting, 2) participants, 3) task, 4) text, and 5) topic.

\subsection{Setting}

In this study, the setting referred to the present syllabus of the business communication course; since it formed an overall structure of learning to speak English. As informed by the findings, the existing course syllabus did not seem to profoundly afford the cognition-action complexes that scaffold learners' cognitive development (Atkinson, 2010, p.602), when it provided the students with few opportunities to productively experience the target language. The focus on teacher-led activities not only prevented the students from actively executing their metacognitive strategies, but it also created a learning trajectory that mirrored the complexities of real-life communication (Goh, 2017). 


\subsection{The participants}

The teacher and the peers comprised the in-class community that largely contributed to the students' cognitive operations in the study. Since the teacher was a leading social actor in the classroom, she had full authority to control the students' learning experience, in a manner that might facilitate, or possibly inhibit, their cognitive activities. Hence, when the teacher decided to traditionally teach vocabulary through mechanical language exercises from a textbook, the decontextualised language input might have interrupted the students' neurological operation for negotiating the social world (Mislevy, 2018), which may then have resulted in the students' inability to perform actual communication outside the classroom.

Nevertheless, the findings showed that the teacher managed to develop a positive learning atmosphere, when her engaging personality largely satisfied the students' psychological needs. This constructive relationship was, however, lacking among the students, when they reported feeling demotivated by their peers' unsupportive actions in the classroom. This may suggest that in-class communities are not just other beings that share similar social activities; but they are also a group of people, whose emotions are internally attached to function rationally (Damasio, 1994).

\subsection{The Task}

The task in this study was defined as an activity that involves learners' active engagement in complex thinking, and which focuses mainly on the notion of meaning, rather than merely on form (Ellis, 2012). As such, the form-focused exercises that took place during the vocabulary learning cannot be regarded as tasks, when they put the students in an idle mood almost every time. This indicates the inert structuring of knowledge in an isolated cognitive space (Atkinson, 2014), which can put the whole process of learning at risk; since intelligence is acquired through performance (Atkinson, 2002; Barrot, 2013).

Notwithstanding the foregoing, there were still tasks available in the observed speaking classroom, when the students were asked to perform role-plays. These activities, were, however, rather unsatisfactory when the role-playing presentation left many students, especially those with restricted proficiency, feeling uneasy. These unpleasant feelings can be very destructive to their learning of spoken English; since emotions affect one's cognition/learning (Damasio, 1994).

\subsection{The text}

This study described text as the types of language the students used throughout the learning activities. Since there was little interaction that had occurred during the form-focused exercises, there was no significantly spoken text produced during this event. On the other hand, there were two forms of text recorded during the role-playing tasks: 1) an informal conversation with a partner during the discussion, and 2) a formal conversation with the partner during the presentation. While these two texts were produced in the same activity of roleplaying, the difference in the task formally evoked different emotional reactions in the students. 
The higher degree of public attention gained during the presentation caused the less-proficient students to feel highly anxious; and, thus, they adopted some measures that would accommodate their restricted language abilities (i.e. to read scripts). This illustrates the complex neural mechanisms of learners that are situationally and emotionally determined (Perlovsky, 2011).

\subsection{The topic}

As depicted in the findings, the topics of speaking activities had the capacity to reinforce learning, when they so often led to better learner engagement. This is probably because meaning/knowledge is latent in human cognition; and it would only be activated following some input stimulus and former experiences (Atkinson, 2002). Hence, when the students were asked to speak about something that was knowledgeable to them, a set of previously socialised neural connections might have been prompted to mediate meaning-making; and this thereby helped them to actively fit into the L2 system.

The largest dotted circle in Figure 5.1 signifies the cultural context that this study did not set out to investigate, but nevertheless appeared in the findings. The students' positive behaviours in the classroom, to respect the teacher, might reflect their conformity to the norms of Malay Islamic society that highly values good manners (Chuchu \& Mahali, 2014). However, since the susceptibility of neural schemas to one's personal experiences of the world can sometimes turn the idiosyncratic mind against the dominant ideologies (Atkinson, 1999, p.642), some students seemed not to be culturally conditioned when their similar executed actions were found to derive their own interests, rather than those of society.

\subsection{The underlying forces of adaptation and alignment}

According to the socio-cognitive theory, the symbiotic interdependence between cognition and the socio-material world denotes the socio-cognitive process of alignment, or the complex means by which human beings effect co-ordinated interaction and maintain the interaction in dynamically adaptive ways (Atkinson et al., 2007, p.169). Following this, the students' embodied learning actions in this study, depicted their continuous and progressive drives to be aligned with the various opportunities available in the L2 classroom environment.

The meta-analysis of the findings revealed that the students' goal-directed actions, or strategic competence varied, according to their L2 abilities. Students with restricted English knowledge were likely to use the L1, rather than the L2 during the discussion activities, in order to help them complete the task. Their intention to use the L1 to create meanings showed the students' attempt to align with the assigned task procedures; and since their L2 abilities were insufficient to perform such actions in the L2, their intuition must have been prompted to allow them to invoke their L1 properties for a shared cognition, or for intersubjective reasons (Atkinson, 2002).

The students' low self-confidence also made it difficult for them to naturally align their L2 with that of their partner, when they decided to read from their scripts during the role-playing presentation. This move could be harmful; as it not only left the students with few opportunities to negotiate meanings with their local 
counterpart, but it also failed to represent the social reality of language - to respond to other social beings via turn-taking, gaze and bodily positionings (Levinson, 2006).

The situation with the more proficient students, was, however, quite the reverse, wherein they displayed a more promising strategic competence. Their privileged access to L2 acquaintances might have enhanced their self-confidence to swiftly align their target-language use with that of their partner. This enabled them to substantially adapt to and become a part of the situated L2 system (Atkinson, 2002, 2011), and, thus, to survive in the emotionally threatening presentation activities.

All in all, it is, therefore, reasonable to draw a conclusion that the existing L2 microsystem was rather ineffective in scaffolding the less-skilled students' cognitive development. The presence of nerve-wracking classroom events (e.g. role-playing presentation in an unsupportive environment) had noticeably put the less-competent students under stress, resulting in them focusing more on adapting to immediate circumstances that were highly necessary in the classroom. Given that their nervous minds had always forced them to resort to many detrimental learning actions, these students might well have missed their opportunity to grow in the real L2 world outside the classroom.

\section{Conclusion}

Following the socio-cognitive perspective of SLL, the entire process of learning to speak English exemplified a default state of human affairs within a complex integrated system. As shown by the SM model proposed in the study, the learners' capacity as intellectual social individuals obliged them to impulsively interact with the multi-facetted external constituents, as part of their adaptive efforts to align with the demanding L2 classroom environment, irrespective of the intertwined interactions that occurred in the researched system. Furthermore, it was found that the in-class L2 surroundings were tactically inept at mediating learners' cognitive operations, when a strong sentiment of worry constantly arose in less-competent students, resulting in their harmful adaptive behaviours.

Accordingly, this study emphasised the necessity for ESL teachers to acknowledge the all-embracing constructs of socio-cognition, as the core factors that determine the pedagogical process of learning spoken English; and making sure that that all social agents and properties in the classroom environment are supportive of learners' "higher-order" cognitive activities, are a must. Although this case study, at some points, managed to provide a rich, contextualised understanding of some aspects of L2 learners' learning experiences, it is still bounded by the limitations of those qualitative findings, which cannot be generalised beyond the specific learners and the immediate context of the research. Consequently, a mixed-methods approach that combines the findings from both quantitative and qualitative studies, is perhaps warranted for such studies in the future. 


\section{Acknowledgments}

This work was supported by a research grant (STRG) provided by Universiti Malaysia Kelantan (R/FUND/A0400/00634A/001/2020/00836).

\section{References}

Abdul Hamid, M. S., Islam, R., \& Hazilah, A. M. (2014). Malaysian graduates' employability skills enhancement: An application of the importance of performance analysis. J. for Global Business Advancement, 7(3), 181-197. https://doi.org/10.1504/jgba.2014.064078

Atkinson, D. (1999). TESOL and 'culture'. TESOL Quarterly, 33(4), 625-654. https:// doi.org/10.2307/3587880

Atkinson, D. (2002). Towards a socio-cognitive approach to second language acquisition. Modern Language Journal, 86(4), 525-545. https://doi.org/10.1111/15404781.00159

Atkinson, D. (2010). Extended, embodied cognition and second-language 'acquisition'. Applied Linguistics, 31(5), 599-622. https:/ / doi.org/10.1093/applin/amq009

Atkinson, D. (2011). A socio-cognitive approach to second-language acquisition: How mind, body, and world work together in learning additional languages. Routledge-Atkinson, D., Churchill, E., Nishino, T., \& Okada, H. (2007). Alignment and interaction in a socio-cognitive approach to second-language 'acquisition'. Modern Language Journal, 91(2), 169-188. https:// doi.org/10.1111/j.1540-4781.2007.00539.x

Atkinson, D., Churchill, E., Nishino, T., \& Okada, H. (2018). Language learning great and small: Environmental support structures and learning opportunities in a sociocognitive approach to second-language acquisition/teaching. Modern Language Journal, 102(3), 471-493. https://doi.org/10.1111/modl.12496

Chuchu, D. F. H. A., \& Mahali, S.N. (2014). Politeness in advertisements: Based on nonverbal cues. Proceedings of SOCIOINT14, Turkey.

Baba, R. (2013). Teaching proper English to Malaysian speakers: Focusing on the vowels, consonants, syllables, and stress. US-China Foreign Language, 11(4). https://doi.org/10.17265/1539-8080/2013.04.002

Bachman, L. F. (1990). Fundamental considerations in language- testing. Oxford University Press.

Bachman, L. F., \& Palmer, A. S. (1996). Languag-testing in practice: Designing and developing useful language tests. Oxford University Press.

Baharum, H. I. (2013). Learning business English in virtual worlds: Effectiveness and acceptance in a Malaysian context [Doctoral thesis, Management Information Systems, Massey University, Palmerston North].

Baldwin, D. A., Markman, E. M., Bill, B., Desjardins, R. N., Irwin, J. M., \& Tidball, G. (1996). Infants' reliance on a social criterion for establishing word-object relations. Child Development, 67(6), 3135- 3153. https://doi.org/10.2307/1131771

Barnard, R. (2010). Activity theory: A framework for analysing intercultural academic activity. Action: An International Journal of Human Activity Theory, (3), 25-37.

Barrot, J. S. (2013). A macro perspective on key issues in English as Second Language (ESL) pedagogy in the post-method era: Confronting challenges through a sociocognitive-transformative approach. Asia-Pacific Educational Research, 23(2), 435449. https://doi.org/10.1007/s40299-013-0119-4

Battista, A. (2015). Activity theory and analyzing learning in simulations. Simulation $\mathcal{E}$ Gaming, 46(2), 187-196. https://doi.org/10.1177/1046878115598481

Block, D. (2003). The social turn in second-language acquisition. Edinburgh University Press. 
Canale, M., \& Swain, M. (1980). Theoretical bases of communicative approaches to secondlanguage teaching and testing. Applied Linguistics, 1, 1-47.

Chapelle, C., Grabe, W., \& Berns, M. (1997). Communicative language proficiency: Definition and implications for TOEFL 2000. Educational Testing Service.

Cohen, A. D., \& Dörnyei, Z. (2002). Focus on the language learner: Motivation, styles and strategies. In N. Schmitt (ed), An introduction to applied linguistics. Arnold.

Cohen, A. D. (2010). Focus on the language learner: Styles, strategies and motivation. In N. Schmitt (ed), An introduction to applied linguistics. Hodder Education.

Damasio, A. R. (1994). Descartes' error: Emotion, reason and the human brain. Avon Books.

Driscoll, D. L. (2011). Introduction to primary research: Observations, surveys, and interviews. In C Lowe \& P Zemliansky (Eds.), Writing spaces: Readings on writing (vol. 2), Parlour Press.

Ellis, R. (2012). Language teaching research and language pedagogy. John Wiley \& Sons Inc. Wiley- Blackwell.

Fogassi, L. (2011). The mirror-neuron system: How cognitive functions emerge from motor organization. Journal of Economic Behavior and Organization, 77(1), 66-75. https://doi.org/10.1016/j.jebo.2010.04.009

Foot, K. A. (2014). Cultural-historical activity theory: Exploring a theory to inform practice and research. Journal of Human Behavior in the Social Environment, 24(3), 329-347. https://doi.org/10.1080/10911359.2013.831011

Ganeson, D. (2018). A needs analysis of English for business students at a private university in Malaysia [Master thesis, Faculty of Languages and Linguistics, University of Malaya, Kuala Lumpur].

Gee, J.P. (1992). The social mind. Bergin \& Garvey.

Goh, C. C. M. (2017). Research into practice: Scaffolding learning processes to improve speaking performance. Language Teaching, 50(2), 247-260. https://doi.org/10.1017/s0261444816000483

Gustafsson, J. (2017). Single case studies vs. multiple case studies: A comparative study [Thesis, Halmstad University, Sweden].

Harnish, R. (2002). Minds, brains, computers. Blackwell.

Harsch, C. (2017). Proficiency. ELT Journal, 71(2), 250-253.

Hasan, H., \& Kazlauskas, A. (2014). Activity theory: Who is doing what, why and how. In H. Hasan (ed), Being Practical with theory: A Window into Business Research. University of Wollongong.

Hiver, P., \& Al-Hoorie, A.H. (2016). A dynamic ensemble for second-language research: Putting complexity theory into practice. Modern Language Journal, 100(4), 741-756. https://doi.org/10.1111/modl.12347

Hutchins, E. (1995). Cognition in the wild. MIT Press.

Hymes, D. (1971). Competence and performance in linguistic theory. In R. Huxley \& E. Ingram (eds), Language acquisition: Models and methods. Academic Press.

Jamshed, S. (2014). Qualitative research method-interviewing and observation. Editorial, 5(4), 87. https:// doi.org/10.4103/0976-0105.141942

Khamis, N., \& Wahi, W. (2021). Enhancing business communication skills: An action research. International Journal of Asian Social Science, 11(7), 355364. https://doi.org/10.18488/journal.1.2021.117.355.364

Kitzinger, J. (1994). The methodology of focus groups: The importance of interaction between research participants. Sociology of Health, 16(1), 103-121.

Kitzinger, J. (1995). Introducing focus groups. British Medical Journal, 311, 299-302. https://doi.org/10.1111/1467-9566.ep11347023 
Lantolf, J. P. (2000a). Socio-cultural theory and second-language learning. Oxford University Press.

Lantolf, J. P. (2000b). Second-language learning as a mediated process. Language Teaching, 33(2), 79-96. https://doi.org/10.1017/s0261444800015329

Lantolf, J. P., Poehner, M. E., \& Swain, M. (eds). (2018). The Routledge handbook of sociocultural theory and second-language development. Routledge.

Lee, M. S. (2015). Implementing the socio-cultural theory while teaching ESL. SPACE: Student Perspectives About Civic Engagement, 1(1), 28-35.

Levinson, S. (2006). Cognition at the heart of human interaction. Discourse Studies, 8(1), 85- 93. https:// doi.org/10.1177/1461445606059557

Luoma, S. (2004). Assessing speaking. Cambridge University Press.

Ma, R., \& Oxford, R. (2014). A diary study focusing on listening and speaking: The evolving interaction of learning styles and learning strategies in a motivated, advanced ESL learner. System, 43, 101-113. https://doi.org/10.1016/j.system.2013.12.010

Mislevy, R. J. (2018). A socio-cognitive perspective', in R.J. Mislevy (eds), Socio-cognitive foundations of educational measurement. Routledge.

Nyumba, O., Wilson, T., Derrick, C. J., \& Mukherjee, N. (2018). The use of focus-group discussion methodology: Insights from two decades of application in conservation. Methods in Ecology and Evolution, 9(1), 20-32. https:// doi.org/10.1111/2041-210x.12860

Ortega, L. (2013). Cognition. In B. Comrie \& G. Corbett (eds), Understanding secondlanguage acquisition (pp. 82-109). Routledge.

Oxford, R. (2013). Teaching and researching language-learning strategies. Routledge.

Palinkas, L. A., Horwitz, S. M., Green, C. A., Wisdom, J. P., Duan, N., \& Hoagwood, K. (2013). Purposeful sampling for qualitative data collection and analysis in mixedmethod implementation research. Administration and Policy in Mental Health and Mental Health Services Research, 42(5), 533-544. https://doi.org/10.1007/s10488013-0528-y

Perlovsky, L. (2011). Language and cognition interaction neural mechanisms. $\begin{array}{llll}\text { Computational Intelligence } & \text { and }\end{array}$ https:// doi.org/10.1155/2011/454587

Piggin, G. (2012). What are our tools really made of? A critical assessment of recent models of language proficiency. Polyglossia, 22, 79-87.

Rethinasamy, S., \& Chuah, K.M. (2011). The Malaysian University English Test (MUET) and its use for placement purposes: A predictive validity study. Electronic Journal of Foreign Language Teaching, 8(2), 234-245. https:// doi.org/10.2139/ssrn.2146007

Seong, Y. (2014). Strategic competence and L2 speaking assessment. Teachers College, Columbia University Working Papers in TESOL; Applied Linguistics, 14(1), 13-24.

Stake, R. E. (1995). The art of case-study research. Sage.

Suzuki, Y., Nakata, T., \& Dekeyser, R. (2019). Optimizing second-language practice in the classroom: Perspectives from cognitive psychology. The Modern Language Journal. https:// doi.org/10.1111/modl.12582

Tae-Young, K. (2007). Second-language learning motivation from an activity-theory perspective: Longitudinal case studies of Korean ESL students and recent immigrants in Toronto [Doctoral thesis, Ontario Institute for Studies in Education, University of Toronto, Toronto, Canada].

Tomasello, M. (2014). The ultra-social animal. European Journal of Social Psychology, 44(3), pp. 187-194. https://doi.org/10.1002/ejsp.2015 
Tratnik, A., Urh, M., \& Jereb, E. (2017). Student satisfaction with an online and a face-toface Business English course in a higher education context. Innovations in Education and Teaching International, 56(1), 36-45. https://doi.org/10.1080/14703297.2017.1374875

Van Patten, B., \& Benati, A.G. (2015). Key terms in second-language acquisition ( $\left.2^{\text {nd }} \mathrm{edn}\right)$. Bloomsbury Publishing.

Wei, L. (2018). Trans-languaging as a practical theory of language. Applied Linguistics, 39(1), 930. https://doi.org/10.1093/applin/amx039

Wiley, T.G., \& García, O. (2016). Language policy and planning in language education: Legacies, consequences, and possibilities. Modern Language Journal, 100(1), p. 48-63. https://doi.org/10.1111/modl.12303

Xu, Q., Chen, S., Wang, J., \& Suhadolc, S. (2021). Characteristics and effectiveness of teacher feedback on online business English oral presentations. The Asia-Pacific Education Researcher, 30(6), 631-641. https://doi.org/10.1007/s40299-021-00595-5

Yilmaz, K. (2013). Comparison of quantitative and qualitative research traditions: Epistemological, theoretical, and methodological differences. European Journal of Education, 48(2), 311-325. https://doi.org/10.1111/ejed.12014

Yin, R. K. (2009). Case-study research: Design and methods ( $4^{\text {th }}$ edn). Sage.

Yin, R. K. (2014). Case-study research: Design and methods (5thedn). Sage.

Zhang, L. (2018). Development of the framework of language use. In L. Zhang, Metacognitive and cognitive strategy use in reading comprehension a structural-equation modelling approach. Springer.

Zhang, W., Zhang, L. J., \& Wilson, A. J. (2021). Supporting learner success: Revisiting strategic competence through developing an inventory for computer-assisted speaking assessment. Frontiers in Psychology, 12. https://doi.org/10.3389/fpsyg.2021.689581 